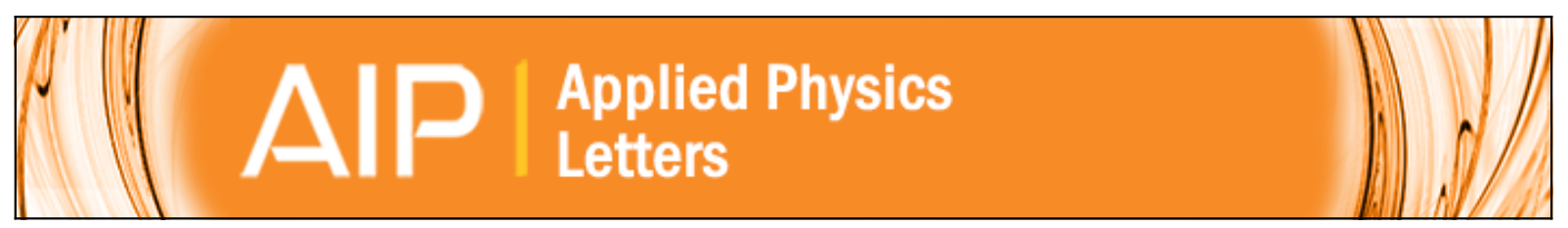

\title{
Submicron mass spectrometry imaging of single cells by combined use of mega electron volt time-of-flight secondary ion mass spectrometry and scanning transmission ion microscopy
}

Zdravko Siketić, Ivančica Bogdanović Radović, Milko Jakšić, Marijana Popović Hadžija, and Mirko Hadžija

Citation: Applied Physics Letters 107, 093702 (2015); doi: 10.1063/1.4930062

View online: http://dx.doi.org/10.1063/1.4930062

View Table of Contents: http://scitation.aip.org/content/aip/journal/apl/107/9?ver=pdfcov

Published by the AIP Publishing

\section{Articles you may be interested in}

Two-dimensional and three-dimensional dynamic imaging of live biofilms in a microchannel by time-of-flight secondary ion mass spectrometry

Biomicrofluidics 9, 031101 (2015); 10.1063/1.4919807

Time-of-flight secondary ion mass spectrometry with transmission of energetic primary cluster ions through foil targets

Rev. Sci. Instrum. 85, 033107 (2014); 10.1063/1.4869036

Time-of-flight secondary ion mass spectrometry chemical imaging analysis of micropatterns of streptavidin and cells without labeling

J. Vac. Sci. Technol. A 24, 1203 (2006); 10.1116/1.2206191

Erratum: "Comparison of the submicron particle analysis capabilities of Auger electron spectroscopy, time-offlight secondary ion mass spectrometry, and scanning electron microscopy with energy dispersive x-ray spectroscopy for particles deposited on silicon wafers with one micron thick oxide layers" [J. Vac. Sci. Technol. A 16, 1825 (1998)]

J. Vac. Sci. Technol. A 16, 3148 (1998); 10.1116/1.581477

Comparison of the submicron particle analysis capabilities of Auger electron spectroscopy, time-of-flight secondary ion mass spectrometry, and scanning electron microscopy with energy dispersive x-ray spectroscopy for particles deposited on silicon wafers with $1 \mu \mathrm{m}$ thick oxide layers

J. Vac. Sci. Technol. A 16, 1825 (1998); 10.1116/1.581417

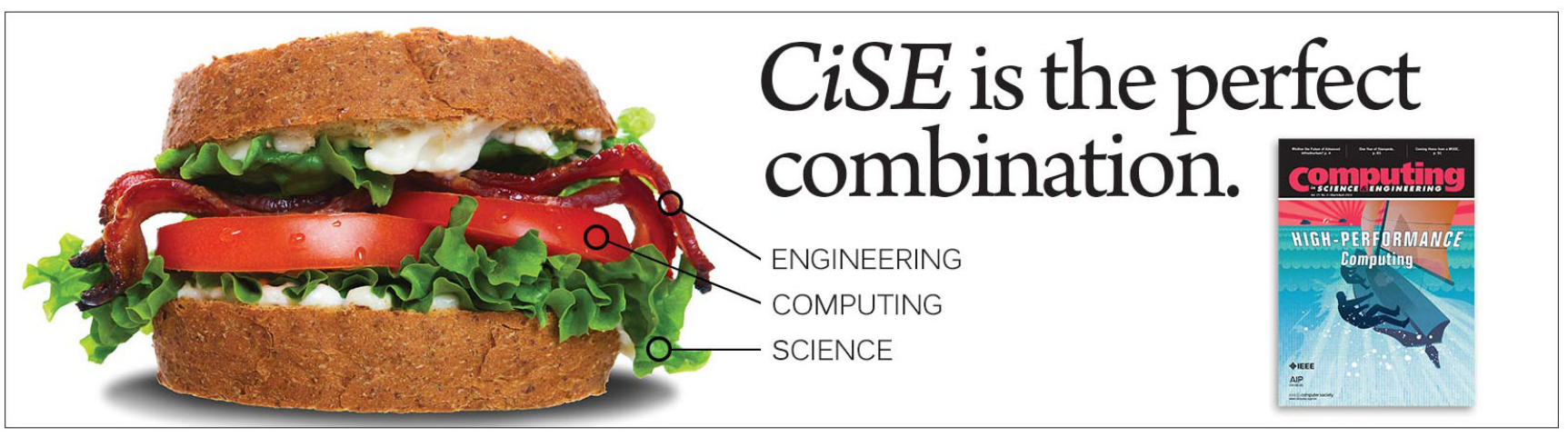




\title{
Submicron mass spectrometry imaging of single cells by combined use of mega electron volt time-of-flight secondary ion mass spectrometry and scanning transmission ion microscopy
}

\author{
Zdravko Siketić, Ivančica Bogdanović Radović, Milko Jakšić, Marijana Popović Hadžija, \\ and Mirko Hadžija \\ Ruđer Bošković Institute, Bijenička cesta 54, 10000 Zagreb, Croatia
}

(Received 20 May 2015; accepted 22 August 2015; published online 1 September 2015)

\begin{abstract}
In order to better understand biochemical processes inside an individual cell, it is important to measure the molecular composition at the submicron level. One of the promising mass spectrometry imaging techniques that may be used to accomplish this is Time-of-Flight Secondary Ion Mass Spectrometry (TOF-SIMS), using MeV energy heavy ions for excitation. MeV ions have the ability to desorb large intact molecules with a yield that is several orders of magnitude higher than conventional SIMS using $\mathrm{keV}$ ions. In order to increase the spatial resolution of the $\mathrm{MeV}$ TOF-SIMS system, we propose an independent TOF trigger using a STIM (scanning transmission ion microscopy) detector that is placed just behind the thin transmission target. This arrangement is suitable for biological samples in which the STIM detector simultaneously measures the mass distribution in scanned samples. The capability of the MeV TOF-SIMS setup was demonstrated by imaging the chemical composition of CaCo-2 cells. C 2015 AIP Publishing LLC.
\end{abstract}

[http://dx.doi.org/10.1063/1.4930062]

Mass spectrometry techniques serve as indispensable analytical tools in the investigation of molecular metabolic pathways that are essential for maintaining cell physiology. In addition to chemical analysis, mass spectrometry imaging (MSI) techniques, such as matrix-assisted laser desorption/ ionization mass spectrometry (MALDI-MS) ${ }^{1-3}$ and secondary ion mass spectrometry (SIMS), ${ }^{4-6}$ could also provide information regarding molecular distributions at the microscopic level. The minimum analyzed area for chemical imaging using MSI techniques depends mainly on two factors: the minimum achievable beam spot size and the sensitivity, which is the total number of molecules that can be detected in the beam spot before the sample surface is destroyed. Despite the good sensitivity of MALDI, which uses a matrix to enhance the ionization probability, the spatial resolution of the laser beam spot is in the range of $5-10 \mu \mathrm{m}$, with $3 \mu \mathrm{m}$ as the best spatial resolution obtained by analyzing a mouse brain section. ${ }^{7}$ Nevertheless, there is another approach called Scanning Microprobe MatrixAssisted Laser Desorption Ionization (SMALDI), ${ }^{8}$ with laser focus below $1 \mu \mathrm{m}$, but in order to perform high-resolution biological imaging, the limitations in the effective lateral resolution due to matrix application remain to be solved. ${ }^{9}$ Contrary to the MALDI technique, the beam spot size with SIMS is well below $1 \mu \mathrm{m}$, which provides an excellent spatial resolution; however, the sensitivity of the technique is much worse, thereby limiting the spot area under analysis to $\sim 1 \mu \mathrm{m} .{ }^{10}$ Recent developments in $\mathrm{keV}$ cluster ion sources ${ }^{11,12}$ aiming to improve secondary molecular yields have reduced the spatial resolution below $1 \mu \mathrm{m}$. In the work of Kozole et al. ${ }^{13}$ Cheng et al. ${ }^{14}$ and Winograd,${ }^{15}$ progress in the potential use of $\mathrm{C}_{60}{ }^{+}$and $\mathrm{Au}_{3}{ }^{+}$cluster projectiles in the high-resolution (submicron) mass imaging of the individual cells is shown. In addition, Heeren and co-workers from Amolf Institute presented a new approach in MSI, microscope mode imaging, where secondary ions/molecules are detected by the combination of ion optics and position sensitive detector enabling lateral resolution of $\sim 600 \mathrm{~nm} .^{16}$ This approach decouples effective lateral resolution from desorption and ionization spot size, so broad primary beam can be used. It has been recently demonstrated ${ }^{17,18}$ that the use of $\mathrm{MeV}$ primary ions, instead of the $\mathrm{keV}$ energy ions that are used in conventional SIMS, significantly suppressed fragmentation and simultaneously enhanced the secondary ion yield, especially for higher mass molecules (100-1000 Da). An increase in yield of more than three orders of magnitude was demonstrated using peptide samples, making $\mathrm{MeV}$ TOF-SIMS a good candidate to perform molecular imaging at the submicron level. However, similar to MALDI, the beam spot size of the existing MeV TOF-SIMS systems is typically several microns. ${ }^{19-23}$ The main reason for this is that the ion microbeam pulsing (providing the start signal for TOF) requires rather high initial ion beam currents, which are delivered by the accelerator to the ion microprobe. ${ }^{19,20}$

In the recently commissioned MeV TOF-SIMS setup at $\mathrm{RBI},{ }^{21}$ the most commonly used primary beams are oxygen and silicon ions between 5 and $20 \mathrm{MeV}$. In order to obtain a sufficiently narrow pulse width $(<10 \mathrm{~ns})$, which is essential for high mass resolution, the primary ion microbeam current has to be greater than $100 \mathrm{pA}$. This limits the lateral beam resolution to $\sim 10 \mu \mathrm{m}$, due to the large opening of the object and collimator slits that are required. Thus, the minimum spot size for the molecular mapping is limited by the beam spot size, not by the sensitivity of the method.

In order to improve the resolution of the lateral beam, the trigger for the TOF-START was replaced with a timing signal that is provided by a silicon charged particle detector that is used for Scanning Transmission Ion Microscopy (STIM). The STIM detector is normally placed behind the target and is transparent to the ions being used, as seen in 
Fig. 1. The data throughput with pulse processing electronics $(\sim 10 \mathrm{kHz})$ permits measurements with continuous beams of significantly lower beam currents ( $<1 \mathrm{fA})$. Reduction of the beam current is performed by closing the object and collimator slit openings, thus decreasing divergence of the ion beam. This leads to a significant reduction of the ion beam spot size (below $1 \mu \mathrm{m}$ ) using the same focusing elements (Oxford quadrupole triplet). With this approach, the same beam current was achieved as with the pulsed ion beam mode, but the beam lateral dimension was reduced by more than an order of magnitude.

Although the proposed approach requires working with thin samples (transparent for the primary ions being used), another advantage of this setup is that together with the molecular image, a STIM image of the sample is also recorded. This provides information about the sample density distribution, which is essential for biological materials, such as tissue sections or single cells. In addition, the beam dose is easily monitored, because a STIM detector directly counts the number of atoms that strikes each pixel. Altogether, due to the well-defined submicron beam focus and the high sensitivity, molecular imaging of a single cell at a sub-cellular level is now achievable also using MeV TOF-SIMS.

Fig. 1 shows a schematic view and the picture of the experimental setup for the simultaneous TOF-SIMS and STIM measurements. For the TOF-SIMS measurement, a linear TOF spectrometer is positioned at an angle of $135^{\circ}$ toward the beam direction. Additional details regarding the TOF spectrometer can be found in Ref. 21.

The energy of the transmitted ions and the START signal were recorded using a HAMAMATSU PiN diode S1223-01 that is placed $10 \mathrm{~mm}$ behind the sample (STIM

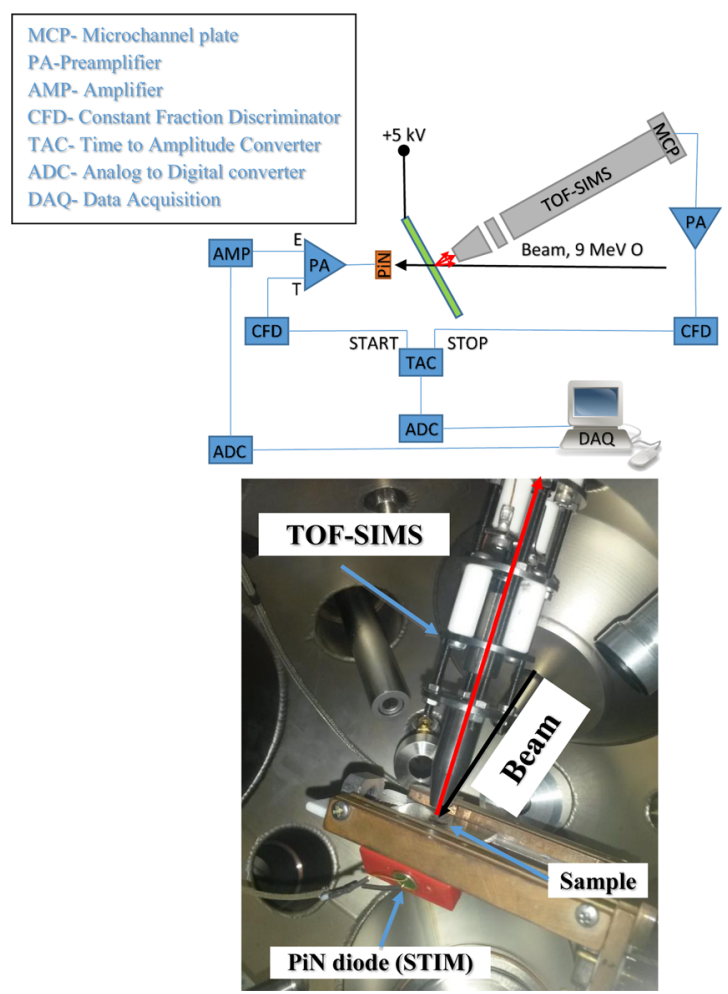

FIG. 1. Schematic view and the picture of the setup for the combined TOFSIMS and STIM measurements. detector). Due to the damage that is induced by the $\mathrm{O}$ ion beam, the spectroscopic characteristics of the PiN diode degrade with accumulated ion fluence. Therefore, the diode should be replaced frequently (for each measurement), which is not a concern due to the low cost. Secondary molecular ions, which are desorbed from the sample surface after interaction with the $\mathrm{MeV}$ primary ions, are accelerated toward the spectrometer with a $+5 \mathrm{kV}$ voltage difference between the target and the extractor. Sample was positioned (focused) by long working distance microscope attached to the microbeam chamber.

The initial tests of the beam's lateral resolution and of TOF-SIMS measurements were performed using a $9 \mathrm{MeV}$ $\mathrm{O}^{4+}$ beam that was accelerated by a $6 \mathrm{MV}$ EN Tandem Van de Graff accelerator. The beam's lateral resolution was deduced from STIM measurements on a Ni-plated grid of known dimensions, as demonstrated in Fig. 2.

The two-dimensional map in Fig. 2 consists of $256 \times 256$ pixels, which corresponds to a scanned area of $27 \times 27 \mu \mathrm{m}^{2}$. Color bar represents the number of events in the pixel. There are no events at the bar position, since it is too thick for ion passage. Beam resolution was calculated by fitting the "error function" on the grid bar edge extracted from the grid image: $(300 \pm 60) \mathrm{nm}$ in the $\mathrm{x}$-direction and $(500 \pm 100) \mathrm{nm}$ in the $y$-direction, respectively. It can be seen that the smallest grid bars (nominally $400 \mathrm{~nm}$ ) are nicely resolved in the $\mathrm{x}$-direction, which demonstrates that the beam resolution is less than $400 \mathrm{~nm}$. The same bars are not visible in the $\mathrm{y}$-direction, which indicates that the beam resolution is worse than $400 \mathrm{~nm}$. One reason for this is because the target is inclined under $45^{\circ}$ to the beam direction, and the beam resolution is diminished in the y-direction by a factor of $2^{1 / 2}$.

Molecular mapping capabilities of the setup were evaluated using a CaCo-2 cell line, which is derived from a human colorectal adenocarcinoma. Thin $(5 \mathrm{~nm}) \mathrm{Au}$ film was evaporated onto the $100 \mathrm{~nm}$ thin silicon nitride $\left(\mathrm{Si}_{3} \mathrm{~N}_{4}\right)$ window $\left(1 \times 1 \mathrm{~mm}^{2}\right.$ window and $5 \times 5 \mathrm{~mm}^{2} \mathrm{Si}$ frame size from the SILSON Company) in order to ensure a uniform extraction field between the target and the spectrometer extractor. The silicon nitride windows and cells $(60000$ cells $/ \mathrm{ml})$ were

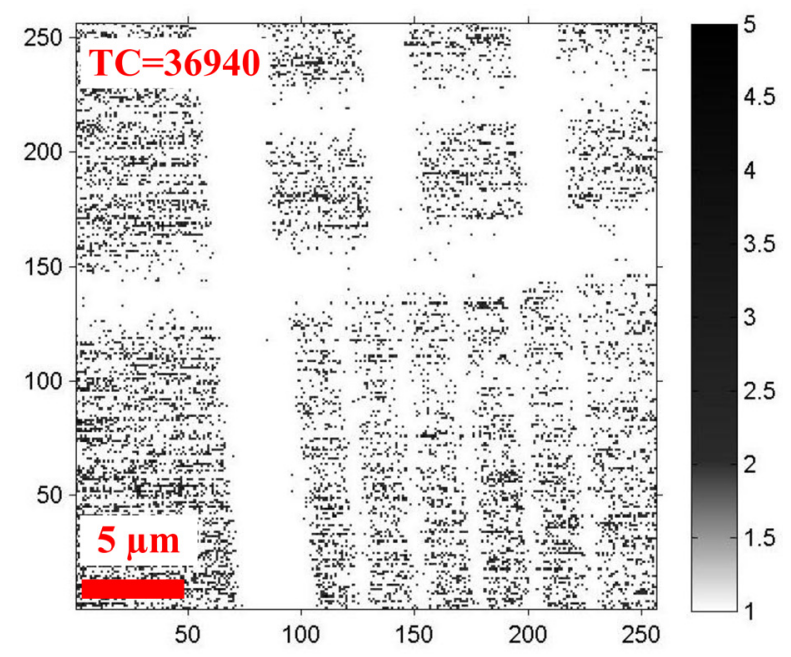

FIG. 2. STIM image of the Ni-plated grid recorded using a $9 \mathrm{MeV} \mathrm{O}^{4+}$ beam, with total count (TC) displayed. 


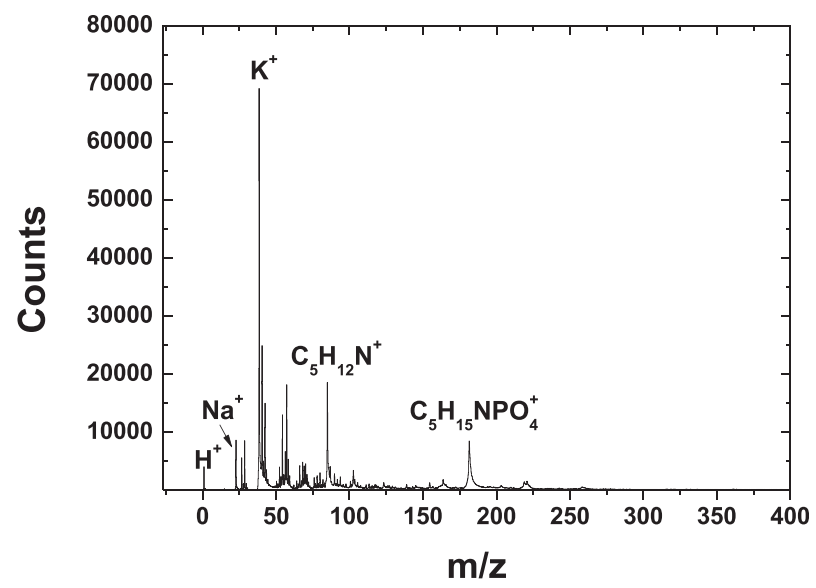

FIG. 3. TOF-SIMS spectra of CaCo-2 cell acquired using a $9 \mathrm{MeV} \mathrm{O}^{4+}$ beam.

placed in glass Petri dishes in complete Dulbecco's Modified Eagle Medium (DMEM) from Gibco ${ }^{\mathrm{TM}}$ (detailed composition can be found at the producer webpage). The cells were grown at $37^{\circ} \mathrm{C}$ with $5 \% \mathrm{CO}_{2}$ on the upper (gold) side of the window for $24 \mathrm{~h}$. Subsequently, the silicon windows with the cells were washed 5 times using a volatile salt solution of ammonium formate (HCOONH4, Sigma, $150 \mathrm{mM}$ ), followed by cryofixation in liquid nitrogen. ${ }^{24}$ Lyophilization (freeze drying) was performed overnight at $-80^{\circ} \mathrm{C}$ at a pressure of $10^{-3}$ mbar (Lyovac GT2E, Steris, Germany), and the silicon nitride windows were stored in a drying chamber until used. The TOF-SIMS spectrum acquired from the cellular region is shown in Fig. 3.

The most pronounced peaks in the spectra were identified and were shown to exhibit the typical composition of a biological sample: ${ }^{25} \mathrm{Na}^{+}$and $\mathrm{K}^{+}$ions, and lipid fragments at masses $86.1\left(\mathrm{C}_{5} \mathrm{H}_{12} \mathrm{~N}^{+}\right)$and $184.1\left(\mathrm{C}_{5} \mathrm{H}_{15} \mathrm{NPO}_{4}{ }^{+}\right)$. Mass resolution of our present linear TOF instrument is only $\sim 1$ / $500,{ }^{21}$ so peaks are not defined with a high precision. Since analyzed sample was pure CaCo- 2 cell, we assigned peak at mass of 184.1 to a fragment of phospholipid, which is naturally occurring in biological samples.

Fig. 4 displays a 2D distribution of $\mathrm{Na}^{+}, \mathrm{K}^{+}$, and lipid fragments together with the STIM image of $\mathrm{CaCo}-2$ cell. A corresponding optical image is also shown.

CaCo-2 cells were grown attached to the silicon nitride window, maintaining the same shape as in a culture flask (Fig. 4 optical image). A higher peak of potassium than sodium ions obtained in the SIMS spectra of CaCo-2 cells is in accordance with sodium/potassium gradient that exists in a living cell due to preserved function of active ion pumping and channels across the plasma membrane. The higher potassium peak is observed in, e.g., human fibroblasts, ${ }^{24}$ although the exact $\mathrm{K} / \mathrm{Na}$ ratio could vary due to the difference in cells types, a level of cellular metabolic activity, and the type of medium used for cell culture (high or low glucose). Signal background $\left(\mathrm{Na}^{+}, \mathrm{K}^{+}\right.$, and lipids) is expected due to how $\mathrm{CaCo}-2$ cells are growing. They grow in the clusters and it is hard to separate individual cell from the signal coming from the surrounding cells.

The scan size of the images in Fig. 4 is $85 \times 85 \mu \mathrm{m}$, which corresponds to $\approx 330 \mathrm{~nm} / \mathrm{pixel}$. The color bars next to
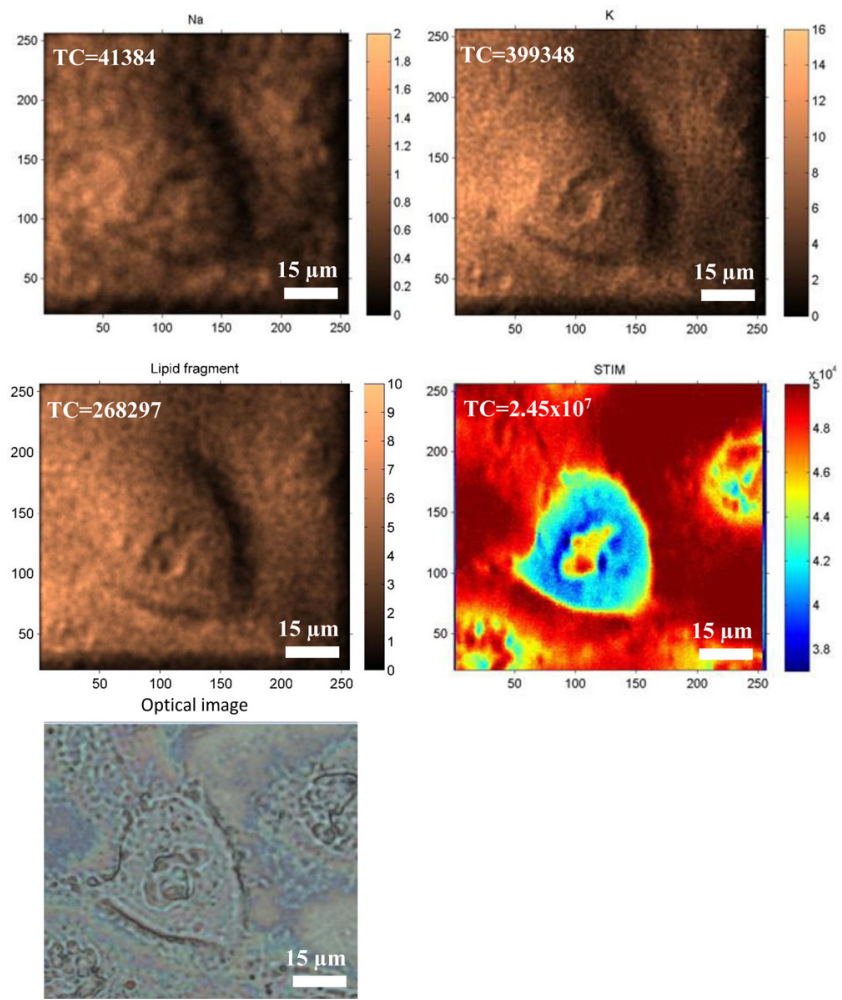

FIG. 4. 2D distribution of $\mathrm{Na}^{+}, \mathrm{K}^{+}$, and lipids in CaCo-2 cell. A STIM image (density distribution) is also presented, together with an optical image. Total number of counts (TC) for each mass is displayed.

each SIMS image represent the number of counts per pixel. In the case of the STIM image, the color bar represents the density distribution within the cell (in arbitrary units), from the highest (blue color, cytoplasm) to the lowest density (red color, nucleus).

If we assume that typical composition of the dehydrated biological sample is $\mathrm{C}_{3} \mathrm{H}_{7} \mathrm{NO}$, with density of $\rho=1.4 \mathrm{~g} \mathrm{~cm}^{-3},{ }^{26}$ range of the $9 \mathrm{MeV} \mathrm{O}$ ions according to the $\mathrm{SRIM}^{27}$ calculations is $6.8 \mu \mathrm{m}$. Since the STIM spectra was collected simultaneously, we found that average thickness of the analysed dehydrated $\mathrm{CaCo}-2$ cell is in a range of $\sim 1 \mu \mathrm{m}$ ( SRIM $^{27}$ calculations).

The yield of the selected masses of the secondary molecular ions as a function of the primary ion flux is shown in Fig. 5.

It can be seen that the yield of secondary molecular ions does not change with the primary ion flux, which indicates that the criteria for static SIMS are preserved.

Normally, the static SIMS limit is in the range of $10^{12}-10^{13}$ ions $/ \mathrm{cm}^{2}$ for $\mathrm{keV} \mathrm{Ar}^{+}, \mathrm{Ga}^{+}$, and $\mathrm{In}^{+}$ions and it can be even lower for the cluster ion sources. ${ }^{28}$ Recently, we performed damage cross section measurements on a pure Leucine sample using $5 \mathrm{MeV}^{28} \mathrm{Si}$ ions showing that static SIMS criteria is preserved for $10^{13}$ ions $/ \mathrm{cm}^{2}$. Therefore, we expect that we can improve statistics for each mass presented in 2D maps (maps where created by $4 \times 10^{11} \mathrm{O}$ ions $/ \mathrm{cm}^{2}$ ).

According to Ref. 23, the minimum yield required for molecular imaging in a $1 \mu \mathrm{m}^{2}$ area is $10^{-4}$. It can be seen from Fig. 5 that the area obtained using MeV TOF-SIMS is well below this value for the molecules in this range, because the lowest yield is $\sim 2 \times 10^{-3}$ for $\mathrm{Na}^{+}$ions. Due to the 


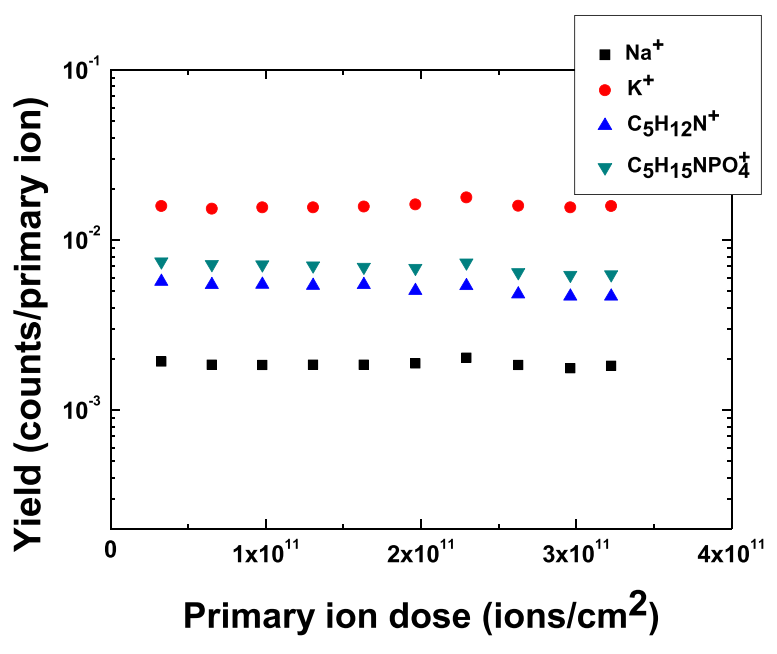

FIG. 5. Secondary molecular ion yield as a function of the primary ion flux.

variety of the primary ion beams and energies which can be chosen, system can be easily tuned in order to obtain the best yield for the dedicated molecule under the investigation. It is worth mentioning that measurements of the secondary ion yield are straightforward when each primary ion is directly detected in the STIM detector, which was not the case for the setup that used a pulsed beam.

From the present data, it can be concluded that this $\mathrm{MeV}$ TOF-SIMS arrangement, which uses a particle STIM detector beyond the target for START triggering, shows great potential for subcellular molecular imaging with a lateral resolution well below $1 \mu \mathrm{m}$. Additionally, STIM images are simultaneously collected, thus providing additional information about the sample density distribution and allows for cellular localization without the use of additional markers. Because the system is very simple, it is readily compatible with existing heavy ion microprobes. An additional advantage is that MeV TOF-SIMS will provide more complete insight of the sample composition compared to analyses performed using standard ion beam techniques such as PIXE or RBS. The only apparent disadvantage is that samples must be thin enough to allow for primary ions to pass through (several microns). Therefore, samples should be mounted on delicate $100 \mathrm{~nm} \mathrm{Si}_{3} \mathrm{~N}_{4}$ windows, which makes sample preparation more difficult in some cases.

We wish to thank Dr. Mira Ristic for the use of the freeze drier and Dr. Ana Šantić for the thin film evaporation equipment. Part of this work was supported by the UKF project "Study of modern paint materials and their stability using MeV SIMS and other analytical techniques," Croatian Center of Excellence for advanced Materials and Sensing devices (CEMS), and the IAEA CRP project "Development of molecular concentration mapping techniques using $\mathrm{MeV}$ focused ion beams."

${ }^{1}$ P. Chaurand and R. M. Caprioli, Electrophoresis 23, 3125 (2002).

${ }^{2}$ M. Stoeckli, D. Staab, M. Staufenbiel, K. H. Wiederhold, and L. Signor, Anal. Biochem. 311, 33 (2002).

${ }^{3}$ C. Marsching, M. Eckhardt, H.-J. Gröne, R. Sandhoff, and C. Hopf, Anal. Bioanal. Chem. 401, 53 (2011).

${ }^{4}$ D. Touboul, O. Laprévote, and A. Brunelle, Curr. Opin. Chem. Biol. 15, 725 (2011).

${ }^{5}$ D. Touboul, F. Halgand, A. Brunelle, R. Kersting, E. Tallarek, B. Hagenhoff, and O. Laprévote, Anal. Chem. 76, 1550 (2004).

${ }^{6}$ K. Börner, P. Malmberg, J. E. Månsson, and H. Nygren, Int. J. Mass Spectrom. 260, 128 (2007).

${ }^{7}$ A. Römpp and B. Spengler, Histochem. Cell Biol. 139, 759 (2013).

${ }^{8}$ B. Spengler and M. Hubert, J. Am. Soc. Mass Spectrom. 13, 735 (2002).

${ }^{9}$ W. Bouschen, O. Schulz, D. Eikel, and B. Spengler, Rapid Commun. Mass Spectrom. 24, 355 (2010).

${ }^{10}$ J. S. Fletcher, N. P. Lockyer, and J. C. Vickerman, Surf. Interface Anal. 43, 253 (2011).

${ }^{11}$ F. Kollmer, Appl. Surf. Sci. 231-232, 153 (2004).

${ }^{12}$ A. Brunelle, D. Touboul, and O. Laprévote, J. Mass Spectrom. 40, 985 (2005).

${ }^{13}$ J. Kozole, C. Szakal, M. Kurczy, and N. Winograd, Appl. Surf. Sci. 252, 6789 (2006).

${ }^{14}$ J. Cheng, J. Kozole, R. Hengstebeck, and N. Winograd, J. Am. Soc. Mass Spectrom. 18, 406 (2007).

${ }^{15}$ N. Winograd, Anal. Chem. 77, 142A (2005).

${ }^{16}$ K. Chughtai and R. M. A. Heeren, Chem. Rev. 110, 3237 (2010).

${ }^{17}$ Y. Nakata, H. Yamada, Y. Honda, S. Ninomiya, T. Seki, T. Aoki, and J. Matsuo, Nucl. Instrum. Methods Phys. Res. B 267, 2144 (2009).

${ }^{18}$ Y. Nakata, Y. Honda, S. Ninomiya, T. Seki, T. Aoki, and J. Matsuo, J. Mass Spectrom. 44, 128 (2009).

${ }^{19}$ B. N. Jones, J. Matsuo, Y. Nakata, H. Yamada, J. Watts, S. Hinder, V. Palitsin, and R. Webb, Surf. Interface Anal. 43, 249 (2011).

${ }^{20}$ H. Yamada, K. Ichiki, Y. Nakata, S. Ninomiya, T. Seki, T. Aoki, and J. Matsuo, Nucl. Instrum. Methods Phys. Res. B 268, 1736 (2010).

${ }^{21}$ T. Tadić, I. Bogdanović Radović, Z. Siketić, D. D. Cosic, N. Skukan, M. Jaksic, and J. Matsuo, Nucl. Instrum. Methods Phys. Res. B 332, 234 (2014).

${ }^{22}$ L. Jeromel, Z. Siketic, N. Ogrinc Potocnik, P. Vavpetic, Z. Rupnik, K. Bucar, and P. Pelicon, Nucl. Instrum. Methods Phys. Res. B 332, 22 (2014).

${ }^{23}$ T. Seki, Y. Wakamatsu, S. Nakagawa, T. Aoki, A. Ishihara, and J. Matsuo, Nucl. Instrum. Methods Phys. Res. B 332, 326 (2014).

${ }^{24} \mathrm{~J}$. Malm, D. Giannaras, M. O. Riehle, N. Gadegaard, and P. Sjövall, Anal. Chem. 81, 7197 (2009).

${ }^{25}$ J. C. Vickerman and D. Briggs, TOF-SIMS: Materials Analysis by Mass Spectrometry, 2nd ed. (IM Publication LLP and SurfaceSpectra Limited, 2013).

${ }^{26}$ H. J. Whitlow, M. Ren, J. A. van Kan, T. Osipowicz, and F. Watt, Nucl. Instrum. Methods Phys. Res. B 267, 2153 (2009).

${ }^{27}$ J. F. Ziegler, Nucl. Instrum. Methods Phys. Res. B 219-220, 1027 (2004).

${ }^{28}$ E. R. Amstalden van Hove, D. F. Smith, and R. M. A. Heeren, J. Chromotogr. A 1217, 3946 (2010). 